\begin{tabular}{|c|c|c|c|c|c|}
\hline Revista Jangwa Pana & ISSN: $1657-4923$ & Vol. 15 & No. 1 & 117 - 128 & Enero - Junio de 2016 \\
\hline
\end{tabular}

\title{
ARQUEOLOGÍA POR CONTRATO Y NUEVOS CONTRATOS ARQUEOLÓGICOS
}

\section{CONTRACT ARCHAEOLOGY AND NEWS ARCHAEOLOGICAL CONTRACTS}

\author{
Wilhelm Londoño ${ }^{1}$
}

\begin{abstract}
RESUMEN
Este artículo discute dos temas que están relacionados. El primer tema es el impacto de la arqueología por contrato en Colombia. Se sabe que la demanda de programas de arqueología preventiva se ha incrementado en los últimos años, pero no se sabe realmente cuánto. La primera parte de este artículo está dedicada a aproximar al lector a esta problemática para el caso colombiano. La segunda parte discute, por medio del análisis de dos sitios arqueológicos, los actuales debates en torno a áreas arqueológicas que involucran políticas de turismo globales y procesos de recuperación locales. El caso de recuperación de un área arqueológica se toma como punto de referencia para hablar de un nuevo contrato arqueológico, que se opone a una arqueología por contrato, que es la tendencia dominante.
\end{abstract}

Palabras clave: Arqueología por contrato; Chairama; Ciudad Perdida; turismo

\section{ABSTRACT}

This paper addresses two topics related to the current situation of archaeology in Latin America and Colombia. The first section of the paper deals with the impact of contract archaeology in Colombia. The fact that programs of contract or preventive archaeology have rocketed in recent years is well known. Less known, however, are the broad tendencies and dimensions of this phenomenon. The second issue discussed here is the relationship between global tourism politics and processes of local recovery and enhancement of heritage assets, which will be explored through the analysis of two archaeological sites. The recovery and touristification of an archaeological site is used as starting point to reflect about the differences between a new tendency in archaeological contract opposed to the dominant tendency in the field.

Keywords: contract archaeology; Chairama; Lost City; tourism

Tipología: Reporte de caso

Fecha de recepción: 04/12/2015

Fecha de aceptación: 28/03/2016

Como citar este artículo: Londoño, W. (2016). Arqueología por contrato y nuevos contratos arqueológicos. Jangwa Pana, 15 (1), 117 - 128

1. PhD. Universidad del Magdalena. Colombia. Correo electrónico: wlondonodiaz@gmail.com 


\section{INTRODUCCIÓN}

$\mathrm{D}$ esde hace unas décadas se viene discutiendo sobre el multiculturalismo como una política que produjo prácticas que giran en torno a la cultura entendida como un bien simbólico que es susceptible de convertirse en un bien con valor de cambio (Gnecco, 2012). La emergencia de las industrias culturales, la revalorización de los centros históricos de las ciudades, la masificación del arte popular, la configuración de los centros de gestión de recursos culturales (CMR por sus siglas en inglés), la arqueología pública (como en Colombia) constituyen síntomas de esta edad que podríamos denominar "la edad del patrimonio". Dentro de estas discusiones es claro que la arqueología, como profesión, se ha amoldado a los tiempos produciendo profesionales capacitados en el manejo técnico de estos recursos culturales. Esto es lo que en otro lugar se denominó la arqueología para el desarrollo (Londoño, 2013), es decir una práctica acrítica y técnica, que se diferencia de la arqueología del desarrollo, que indaga por la manera cómo se imponen los regímenes de verdad. Esta arqueología configura una práctica local, muy circunscrita a ciertos contextos geopolíticos donde se discuten las fronteras disciplinarias y la axiología de la arqueología (Gnecco \& Ayala, 2010). En este documento se explorarán ambas vertientes tomando para ello el caso colombiano. La vertiente instrumental de la arqueología será analizada a través de la revisión de la arqueología por contrato. Para ello se analizará información oficial disponible de las bases de datos del Instituto Colombiano de Antropología e Historia ICANH. Como es sabido, dicho instituto tiene a disposición del público todos los informes arqueológicos que se producen en el país y que corresponden a lo que acá se denomina "arqueología para el desarrollo". En su totalidad, son informes técnicos resultantes del contrato que empresas establecen con arqueólogos para liberar áreas destinadas a proyectos de infraestructura. De tal suerte, se consultó el catalogo en línea para ver cuántos informes producto de programas de arqueología preventiva existían. De ahí se sacaron los datos que se discuten. El filón no instrumental, aquella arqueología que sobrepasa el interés comercial y tiene preocupaciones más comunitarias, será descrito a través de mis experiencias de investigación sobre dos sitios arqueológicos del norte de Colombia: Pueblito Chairama y Ciudad Perdida. Se debe decir que los dos casos son idóneos, pues se encuentran en una misma región, pero comparten trayectorias diferentes que serán remarcadas en la presentación de cada caso. De tal suerte, esta ponderación de la arqueología contemporánea se hace atendiendo las dimensiones cuantitativas del texto, pero también reflexionando, sobre el tópico, desde las espacialidades y las memorias (Hamilakis, 2015).

\section{La arqueología de contrato en Colombia}

En otro lugar (Londoño, 2013) había escrito que la arqueología en Colombia se había movido, en las dos últimas décadas, entre las expresiones mercantiles que trataban de dar insumos técnicos para los proyectos de desarrollo arqueología del desarrollo, y las manifestaciones más locales que versaban sobre las memorias silenciadas y los procesos de su reivindicación arqueología del desarrollo (Londoño, 2013). La esquematización sigue siendo válida. En la actualidad, hay un grupo de arqueólogos que están más allá de los intereses inmediatos de liberar áreas de trabajo de empresas. De otro lado, hay un grupo de personajes críticos (Gnecco \& Ayala, 2010) que cuestionan las visiones técnicas autocontenidas de la arqueología. Entonces lo que ahora se mostrará es cómo ha funcionado la arqueología por contrato en Colombia en sus dimensiones más básicas, cómo su imagen se proyecta en el panorama disciplinario y qué tanto abarca de la producción nacional. El análisis se hizo revisando más de 500 informes que aparecen en el catálogo en línea del Instituto Colombiano de Antropología e Historia ICANH. Para efectos de los análisis, se tomó como palabra clave "programa de arqueo- 
logía preventiva" (PAP). De tal suerte, se desplegó una información que cubre los últimos 7 años culminando en octubre de 2015 que fue la época cuando se recolectó la información. Esto permitió levantar algunas tablas que permiten apreciar rasgos del campo y generan senderos para futuras investigaciones bibliométricas (Gómez, 2005). Hay que señalar que se utilizó esta escala porque dicho periodo es el que está disponible en línea. De todas formas el lapso no es despreciable, sin embargo es evidente que al analizar el 100\% de la información las tendencias podrían variar.
En consecuencia con lo anterior, para documentar el auge de la arqueología por contrato es necesario remitirse a la Figura 1, que se elaboró atendiendo a la revisión de los informes mencionados. Como se puede apreciar, en los últimos 7 u 8 años ha crecido la presentación de programas de arqueología preventiva ante el ICANH. El incremento ha sido sostenido entre el 2010 y el 2015, superándose los 80 programas de arqueología preventiva por año. Esto supone un sesgo en la medida en que es posible que existan otros informes que simplemente no se llamaron con el nombre PAP.

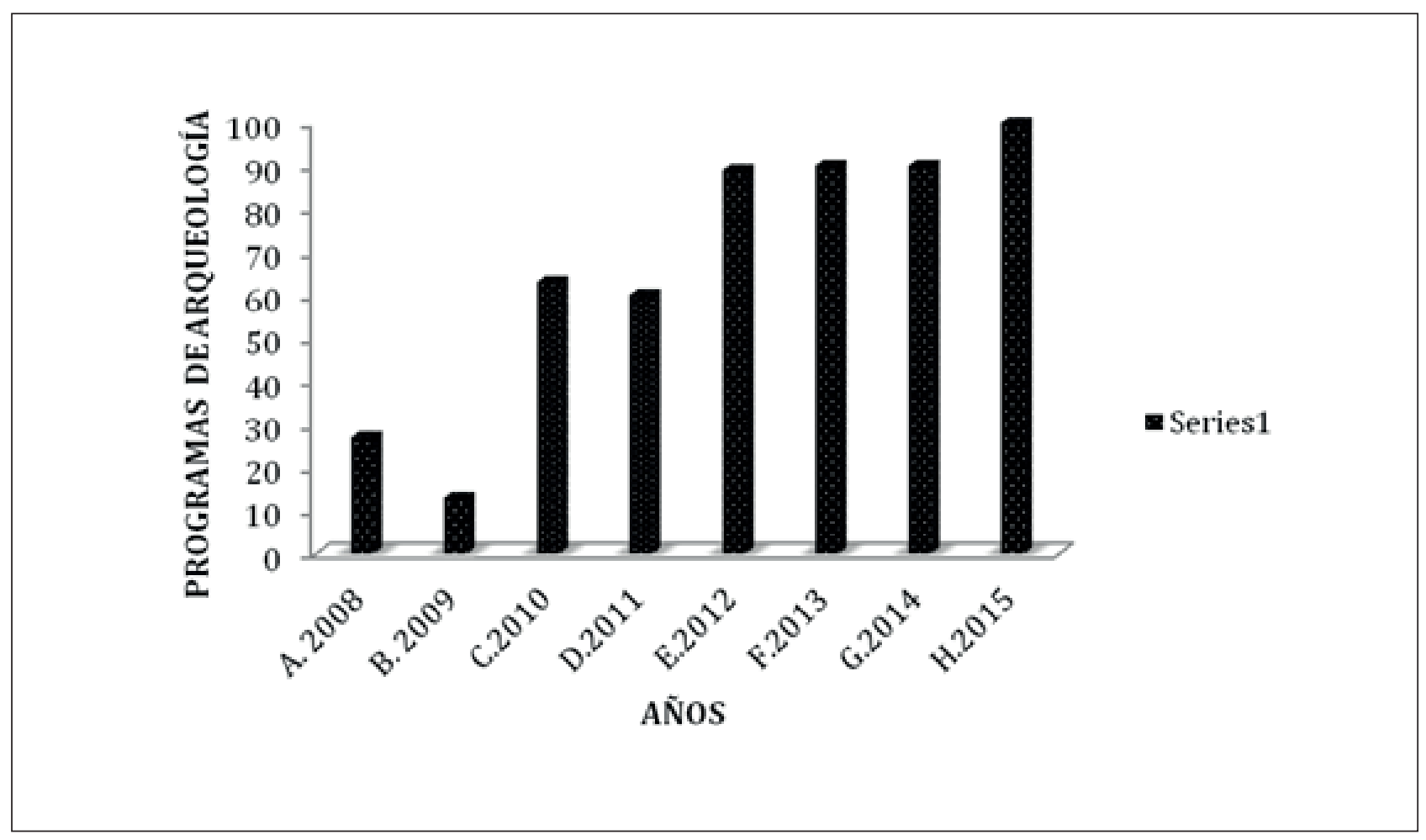

Figura 1. Fuente: Catálogo en línea del ICANH. Análisis del incremento de la arqueología preventiva.

Para ver los sectores donde más dominó la aplicación de estos programas, se utilizó el mismo catálogo y se generó una matriz con los siguientes tipos: A. Hidrocarburos y minas (incluido gas); B. proyectos relacionados con urbanismo; C. proyectos asociados a hidroeléctricas; D. proyectos asociados a construcción de vías; E. canteras de diversos materiales. Se debe señalar que esta aproximación es parcial, pues según los informes que se podían consultar, algunos puertos fueron catalogados en la categoría B (proyectos urbanos) y otros en la A (hidrocarburos). Cuando el proyecto portuario, por ejemplo, decía que era para la exportación de petróleo se dejó en la categoría $\mathrm{A}$; cuando se señala que era multipropósito se dejaba en la categoría B. Incluso en algunos casos ciertas termoeléctricas se categorizaron como tipo B, ya que la principal actividad de estas infraestructuras era proveer de energía localmente. No ocurre lo mismo con la explotación 
minera y la perforación petrolífera, pues estas modificaciones del paisaje no se revierten inmediatamente en infraestructura que impacta en el bienestar regional (Fig. 2). De todas maneras las ambivalencias fueron realmente mínimas sin que lleguen a afectar las tendencias registradas.

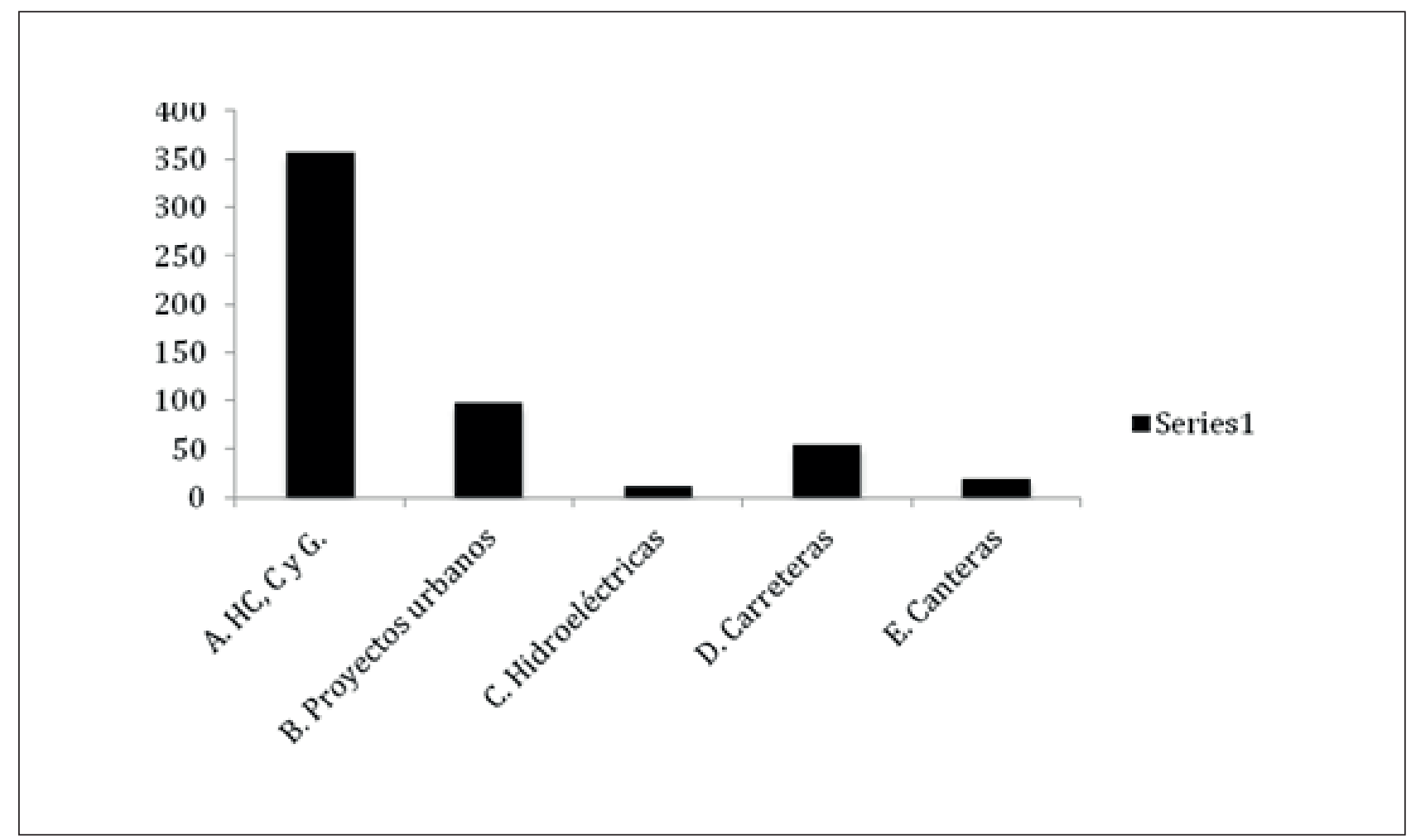

Figura 2. Tipos de informes de Arqueología por contrato en Colombia (2008-2015)

El criterio de categorización es bien interesante porque se evidencia que más del $60 \%$ de la producción de PAP están relacionados con actividades de explotación de hidrocarburos (HC), carbón (C) y gas (G) a cargo de empresas que operan en Colombia para extraer materias primas. De otro lado, casi el 20\% de los PAP corresponden a proyectos locales que, podríamos decir, generan beneficios dobles: a las empresas para poder mover equipos y materias primas, $\mathrm{y}$ a la ciudadanía en general porque se construyen redes que facilitan los procesos de integración espacial y social. De todas maneras, queda clara la tendencia de la arqueología en Colombia que ha sido una profesión entregada totalmente a las demandas de las economías extractivas de orden neocolonial. Esto se mostrará con más claridad adelante, cuando se mencione la producción hecha desde la arqueología científica. Esta tendencia, evidentemente, no sólo se registra a una escala global (Hamilakis, 2005), sino también continental (Haber, 2015).

Un ejercicio que resulta interesante hacer es mirar si la situación de los proyectos de arqueología por contrato tiene algún correlato en la investigación básica, aquella que se publica en las revistas especializadas. Para mirar cómo está el campo por fuera de la empresa privada, se consultaron las revistas de antropología más importantes del país (aquellas que superan la publicación de 10 artículos resultado de investigación por año).

En la Figura 3 se presentan los artículos que contienen la palabra "arqueología" en tres 
de las principales revistas de antropología de Colombia. Estas son: Antípoda (Universidad de los Andes), Revista Colombiana de Antropología (ICANH) y Boletín de Arqueología y antropología (Universidad de Antioquia). Como se puede apreciar en la Figura 3, los mayores picos de publicaciones se dan entre el 2011 y el 2012. Al mirar en detalle qué ocurre, vemos que en estos años aparecen los números especiales de Antípoda, uno dedicado a revisar temas relacionados con el patrimonio (Antípoda, Revista de antropología y arqueología, Universidad de los Andes, enero-junio del 2011), y el otro haciendo una compilación de trabajos de bioantropología (Antípoda, Revista de antropología y arqueología, Universidad de los Andes julio-diciembre de 2011). El hecho de que la preocupación por el patrimonio también fue parte de la agenda de la
Revista Colombiana de Antropología, se percibe en la introducción de una sección específica para patrimonio y arqueología que comienza a aparecer a partir del 2013. De todas formas, lo que más sorprende es que en casi 7 años en estas revistas no aparecieron más de 35 publicaciones relacionadas con arqueología. Esto nos da una frecuencia de casi 5 artículos por año, lo cual es realmente muy bajo para un país donde es posible que se gestionen más de 100 proyectos de arqueología por año. Si se comparan los datos tomados de los PAP con las publicaciones científicas, es claro que de las casi 600 excavaciones oficiales que se realizaron entre el 2008 y 2015 sólo se publicaron, en revistas nacionales especializadas, 35. Entonces esto deja en claro cómo la arqueología en Colombia deja de ser una ciencia para convertirse en una tecnología.

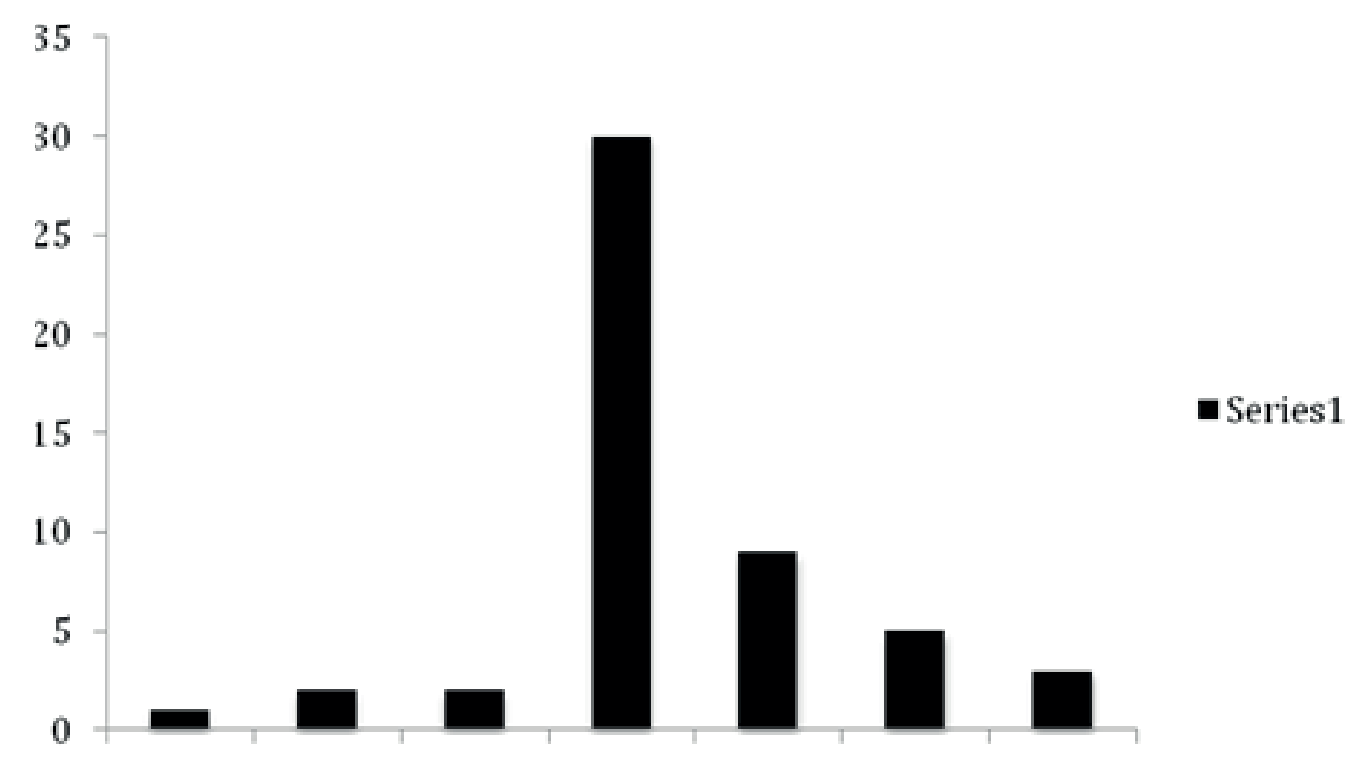

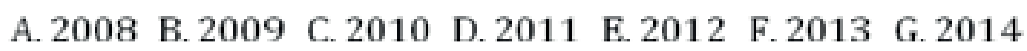

Figura 3. Publicaciones seriadas colombianas que reportan artículos de arqueología (Antípoda, Revista Colombiana de Antropología, y Boletín de Arqueología y Antropología, Universidad de Antioquia) 
Los resultados presentados hasta ahora muestran, claramente, que la producción arqueológica ha sido realmente poca en las ventanas de visibilización escogidas, como son estas revistas. Igualmente, las estadísticas muestran que la arqueología ha sido totalmente cooptada por proyectos de arqueología por contrato orientados a la explotación de hidrocarburos. La proporción es enorme, tal vez por cada artículo de arqueología que sale en una revista de antropología nacional de periodicidad regular (en el marco colombiano de indización entre A1 y A2 lo que garantizan más de una decena de publicaciones resultados de investigación), se hacen más de 70 proyectos de arqueología por contrato.

Definitivamente, hay una eclosión de peticiones para hacer programas de arqueología preventiva y de esta manera las regulaciones oficiales dan materialidad a las demandas de gestión de bienes patrimoniales tal como lo reclama la serie de acuerdos que se dan entre el Estado colombiano y entidades multilaterales como la UNESCO. De esta relación, como está documentado, emerge una tendencia hegemónica donde el patrimonio es manejado únicamente con recursos técnicos, y lo más grave, epistemológicos de tradición occidental, exclusivamente (Byrne, 1991). De esta suerte, preocuparse por los restos materiales del pasado, exigirles a las petroleras que apliquen PAP, incrementar el mercado laboral de los arqueólogos, se concibe como una gestión en el campo de lo cultural. De tal suerte, la cultura se vuelve objeto de manejo, emerge como un patrimonio que demanda atención y cuidado, mientras las condiciones de opresión y generación de desigualdad siguen vigentes (Appadurai, 2000). Como lo ha mostrado Cristóbal Gnecco (2012), en especial para el contexto latinoamericano, el multiculturalismo significó una política de reconocer el otro sin que ese reconocimiento significara cuestionar las condiciones de explotación de esas poblaciones en regiones periféricas como América Latina. Es decir, el Estado garantizó el derecho de los indígenas, afro, población LGTBI, a ser reconocidos por sus elementos identitarios, pero no promovió una política para su protección. Al leer a Gnecco (2012) queda claro que un Estado multicultural no es un estado intercultural.

Otra reflexión que quisiera orientar, es sobre el papel que representan las cifras en el análisis social. Esta presentación numérica de la manera como la arqueología está cooptada por el mercado, no debe permitir dejar pasar por alto las fisuras que deja esta tendencia. Se trata de los espacios-otros (las heterotopías de Michel Foucault) donde esta objetivación de la cultura es superada en una arqueología que rebasa estos estrechos límites propuestos por el mercado. Para ello, como lo advertí al inicio, tomaré un estudio de caso que compromete dos sitios arqueológicos en Colombia: Pueblito Chairama y Ciudad Perdida. El primer sitio permitirá discutir cómo, a pesar de la tendencia hacia un dominio del capitalismo en la gestión patrimonial, en contra de todos los pronósticos, un área denominada como arqueológica está siendo recuperada como lugar sagrado por parte de comunidades kogui. El segundo caso mostrará cómo, siguiendo la tendencia global, el sitio arqueológico Ciudad Perdida está totalmente entregado a las redes del mercado del turismo global.

\section{Pueblito Chairama}

Sobre Pueblito Chairama es poco lo que se ha escrito desde el punto de vista disciplinario y que pueda considerarse definitivo y concluyente. Se encuentran un par de tesis doctorales escritas en la penúltima década (Dever, 2007; Giraldo, 2010) que reseñan ciertos procesos de concentración de cerámicas con otros rasgos que, por el acto mágico de la equivalencia, se relacionan con procesos de concentración política o social. Esto significa que las investigaciones hechas en las últimas décadas, siguiendo los dictámenes de las corrientes procesuales, se han concentrado en procesos de dominación y control político, naturalizando lo que podría denominarse la naturaleza capitalista de los seres humanos (cf. Haber, 2015). 
Pero este espacio no es para discutir lo que el sitio arqueológico supone. En términos generales, se podría decir que el Pueblito se comenzó a construir, por lo menos, un milenio atrás y que su construcción fue gradual y que es muy probable que la profundidad temporal del sitio aumente si se aumentan los fechamientos absolutos. De hecho, el desdén del Estado en el manejo del sitio, supone que aún estén evidencias importantes sin analizarse, como lo demuestran las redes de caminos que conectan al sitio desde diversas partes, las cuales día a día se destruyen sin que se haga una reseña adecuada y se analice su relación con otras evidencias. Para resumir, el sitio no está documentado desde un punto de vista regional porque nadie ha hecho un trabajo regional (Langebaek, 2005). Entonces lo que hay es descripciones parciales del sitio sin que se explique su vinculación con el sistema de paisaje más complejo (una escala apenas deseable para comprender un sitio tan grande como este).

Pero no es la intención pontificar en contra de la mediocridad de la arqueología en tanto profesión que goza de maridaje con el Estado. Creo que las estadísticas que se presentaron arriba deja claro que la arqueología como disciplina, en Colombia, no es una política del Estado o de la academia, o dicho de otra manera hay una política de ceder al mercado la regulación, la inversión, el estudio del patrimonio arqueológico de la nación.

Mi historia con Pueblito (y la licencia biográfica es necesaria cuando hay que resumir experiencias que creemos se dan como hecho sociales, à la Durkheim) data del año 2008 cuando llegué a la Universidad del Magdalena. La primera vez subí con un grupo, caminamos dos horas desde un lugar llamado Calabazo que queda sobre la carretera que lleva de Santa Marta a Riohacha sobre la costa del mar caribe. En el camino fue posible ver una red de caminos desechos por el paso de los burros, caballos y yeguas que cruzan día a día el territorio, así como varias concentraciones de cerámicas al inicio del trayecto y en su intermedio. En ese año, al llegar al sitio, lo encontramos frondoso de vegetación y con ciertas áreas con el pasto rebanado, lo que evidenciaba el mantenimiento del sitio por parte del personal de Parques Naturales Nacionales (PNN). En esos años, uno de los cuidadores, estaba involucrado en el programa de antropología de la Universidad del Magdalena, y de tal suerte, pude saber un poco más sobre qué pasaba realmente con el sitio. Desde hace algún tiempo, el sitio estaba siendo ocupado por un hombre, indígena, de quien se rumoraba tenía un pasado oscuro (Alejandro Suárez, comunicación personal); según se sabía, había llegado a Chairama tras ser desterrado por haber roto reglas matrimoniales o prescripciones religiosas. Esto ha sido muy difícil de precisar. El caso es que después de su llegada, lo acompañaron familiares que comenzaron a ocupar el sitio y a habitar zonas más bajas; se trataba de una re-ocupación del Pueblito Chairama. Al respecto de esta re-ocupación, un líder kogui, Alejandro Nieves, señala que este proceso está conectado con el intento de recobrar las conexiones territoriales que se han roto como consecuencia de los procesos de ocupación (comunicación personal). En este sentido, ciertas familias koguis, siguiendo una política comunitaria, están re-ocupando el sitio con la intención de sobreponerse al modelo de explotación reinante de corte capitalista. Como consecuencia de esta dinámica, en los últimos años vienen dándose fenómenos interesantes como el cierre paulatino de ciertos lugares declarados como áreas sagradas; esto se ha logrado a partir de demadas judiciales instauradas por los indígenas apelando a ciertas leyes multiculturales que se incorporaron con la reforma constitucional de 1991. Sin duda, ha sido un resultado de un proyecto más amplio de re-territorialización de Pueblito Chairama. Hay que señalar que las acciones que adelantan los koguis, están respaldadas por la organización Gonawindúa Tayrona quien aglutina a todos las comunidades indígenas de la Sierra Nevada de Santa Marta. En consecuencia, no se trata de un hecho aislado, sino que responde a una clara política indígena. 
Al respecto de los procedimientos judiciales, varias acciones se interpusieron desde el 2010 de parte de las comunidades indígenas, en especial por líderes koguis, para que Parques Naturales Nacionales de Colombia aceptara que ciertas áreas debían cerrarse a los turistas por ser sagradas. El acto que determinó ese cierre fue la resolución 070 del 28 de febrero del 2013, emitida por el Ministerio de Ambiente y Desarrollo que señaló las áreas que debían delimitarse y cerrarse para "favorecer el bienestar espiritual de los indígenas" (Ministerio de Ambiente y Desarrollo, 2013).

La resolución fue realmente sorprendente y estaba relacionada con ciertas discusiones internas que se daban en torno al manejo que debía tenerse con Pueblito Chairama. Como lo pude comprobar en conversaciones sostenidas con Alejandro Nieves, el foco de la discusión radicaba en la necesidad de reincorporar el sitio a la lógica territorial kogui, de tal suerte que no se concibiera única y exclusivamente con un lugar de turismo. Según la información que pude recabar, todos estos logros se daban en el marco de una política del día al día que involucraba varias familias y colectivos (Montaña, 2012). La meta que se había trazado suponía recuperar lugares determinantes dentro de la territorialidad indígena y que estaban totalmente ocupadas por el desarrollo urbano de la ciudad de Santa Marta.

\section{Ciudad perdida}

El proceso del Pueblito es bien particular si se lo compara con el de "Ciudad Perdida", el sitio arqueológico más importante de la región y de Colombia. Ciudad Perdida, desde las agendas indígenas que se pueden rastrear desde 1999, fue considerado un sitio sagrado y se concebía, desde la óptica local como un lugar que debía trascender el sentido disciplinario de "arqueológico". De hecho, en La declaración conjunta de las cuatro organizaciones indígenas de la Sierra Nevada de Santa Marta para la interlocución con el Estado y la sociedad nacional (Organización wiwa yu- gumaiun bunkwanarrwa Tayrona, Organización indígena kankuama, Organización gonawindua Tayrona \& Confederación indígena tayrona 1999), se especificó, basado en el estudio de la jurisdicción existente, que antes de que un lugar se declarase como arqueológico y que en consecuencia fuese inembargable e inajenable y su declaratoria imprescriptible, debía reconocerse su vinculación primaria con los pueblos declarantes. Para soportar esta argumentación se tomaba como punto de referencia la sentencia constitucional T-428 de 1992, que señalaba que en un pleito entre el interés indígena y el interés de concluir una obra, debía primar el derecho cultural por ser un estandarte de las reformas constitucionales que Colombia adscribió en 1991.

En los años de 2008 y 2009, pude estar presente en algunas reuniones en una de las cuatro organizaciones declarantes de 1999. La agenda era claramente enfática en señalar que el control del sitio debía estar en manos de la comunidad indígena. En el año 2010 se intentó consolidar una reunión de trabajo en Valledupar con miembros del ICANH y las cuatro organizaciones para discutir este tema. La posición del ICANH suponía apelar al criterio del interés general por encima del particular, el indígena. Sin embargo, esos funcionarios estaban discutiendo una agenda aún más problemática, que tenía que ver con la privatización del patrimonio sumergido de la nación y, al final, la reunión se postergó. La presión fue tan incisiva que, a pesar del consenso que había entre arqueólogos colombianos de no ceder la gestión de este recurso a empresas privadas, emergió la ley 1675 de 2013 que permitía remunerar con hallazgos a los buscadores de tesoros. Las partes más nocivas de la ley fueron suprimidas un año después (Corte constitucional de Colombia, 2014), pero el daño ya estaba hecho. En todo caso, lo que deseo señalar es que tanto en la discusión acerca de Ciudad Perdida, como en la del patrimonio sumergido, el debate era cómo poner en escena estos recursos de tal suerte que fueran rentables. En el caso de Ciudad Perdida, las partes en cuestión discutían la propiedad de esa 
renta, pero no se discutía la naturaleza de lugar "turístico". Esto a diferencia de lo que pasa con Chairama donde sí se discute el lugar de turismo.

En este ambiente netamente neoliberal, la reunión de 2010 no se llevó a cabo, no se discutió el carácter de sitio sagrado de Ciudad Perdida, pero en cambio a partir de ese año se dio un viraje fundamental en la política del manejo del lugar que comprometía no sólo a las comunidades indígenas, sino a operadores turísticos. La primera señal de cambio se dio en la consolidación de emprendimientos locales para facilitar la visita a Ciudad Perdida, es decir, aparecieron operadores de turismo indígenas; igualmente en ese año un programa de la agencia de cooperación internacional de Estados Unidos (USAID), financió un puente sobre el río Buritaca, que facilitó la circulación de personas, entre ellas turistas, que permitieron la consolidación de un modelo de gestión comercial. A lo largo del camino de Santa Marta a Ciudad Perdida, lo que toma en promedio 5 días (ida y regreso), hay a la vista unos asentamientos indígenas que se articulan, con campesinos, como proveedores de servicios de turismo. Sin embargo, en la publicidad disponible en la red, como en Santa Marta, estos asentamientos se presentan como "pueblos indígenas ancestrales", lo que da un valor agregado a la visita. Además de esta proliferación de turismo étnico, hay una escuela de arqueología que viene funcionando a cargo de una entidad llamada Global Heritage Fund, en cuyo website se puede leer que su misión es "empoderar a las comunidades a través de la gestión de sus sitios arqueológicos que están en peligro". A pesar de lo loable de la situación, este "empoderamiento" no es más que una estrategia neocolonial que ha supuesto el uso de estándares de gestión económica a las comunidades locales; según algunos datos publicados, esta entidad que "vela" por el patrimonio global ha invertido hasta 400 mil dólares (Guilland \& Ojeda, 2013) en un proceso de gestión privada del patrimonio para Ciudad Perdida. Este modelo implica un aumento del flujo de turistas cuya estadía es soportada por una red de servicios privada. En el caso del puente que se gestionó con USAID, se ha garantizado un flujo constante de turistas que dejan ganancias a las empresas turísticas, a los campesinos, a los indígenas y al ICANH. Según la información que recogí en enero de 2016, aproximadamente 1/20 partes son entregadas a estos actores. Hay que señalar que este modelo no está del todo mal, ha permitido sostener una economía con un recurso que impacta mínimamente en el medio ambiente, y se ha convertido en una fuente importante de bienestar para una comunidad golpeada por el conflicto que vivió la Sierra Nevada de Santa Marta en las década de 1990 y 2000. Lo que me resulta más importante resaltar, es que estos modelos económicos se basan en productos posmodernos como la ancestralidad y la antigüedad, todos artefactos contemporáneos. Además, también resulta importante llamar la atención sobre el papel de la arqueología en estos emprendimientos que ofrecen al turista una imagen idealizada de lo indígena y del pasado que esconde problemas actuales de la región (conflictos entre campesinos e indígenas por territorio, usurpación de territorios indígenas, explotación de áreas sagradas por multinacionales, por ejemplo).

El caso de Ciudad Perdida es, sin duda, sintomático de cómo el mercado se apropia de espacios locales que están vinculados a una óptica particular del mundo, y los transforma en nodos de una red de servicios turísticos que supone la visita a complejos arqueológicos y a comunidades indígenas organizadas para ese fin. Aunque estos procesos son difíciles de rastrear y documentar, por los detalles que comprometen, es evidente que en un periodo corto (un par de años a lo sumo) la postura indígena sobre Ciudad Perdida cambió de una férrea defensa del área como lugar sagrado, a ser considerado un espacio susceptible de explotación comercial. Como lo han enseñado algunos académicos, estos procesos de comercialización de elementos culturales no son muy estudiados, tal vez por la idea de que los indígenas están en contra del capitalismo, lo cual no siempre es cierto (González, 2014). No 
sobra decir que estas imágenes son reproducidas por antropólogos y otros científicos sociales que viene a experimentar la esencialidad de los indígenas, cuando en realidad consumen productos de una compleja red de producción que involucra productores locales e inversores internacionales. Pero a la par de este caso, Pueblito Chairama reproduce otra lógica, otras formas patrimoniales lo que nos permite volcar la mirada hacia alternativas de gestión.

\section{Un nuevo contrato arqueológico: ¿De qué se trata todo esto?}

En cierto lugar, el filósofo esloveno Slavoj Žižek (2011) señalaba que uno de los problemas más acuciantes para la sociedad global contemporánea, era despertar del letargo que el capitalismo generó haciéndonos creer que era en definitiva una opción inevitable y que nada se podía hacer para cambiar. Ese horizonte de subjetividad es bien sintomático. Las series televisivas que se basan en humanos que sobreviven a zombies, sin duda, orientan la mirada hacia una estética de la muerte, el apocalipsis y la resignación: queda sobrevivir. En la sociedad actual globalizada, no sólo proliferan los zombies, sino los cuerpos colonizados por sus propios dueños a través de los tatuajes y las deformaciones, gran síntoma de en dónde es posible la libertad (en el cuerpo, hacia dentro). Este "espíritu de la historia" también se proyecta en la arqueología: Destinada a satisfacer las demandas de las empresas que juegan a cuidar el bien de la nación, a la vez que participan en procesos de neocolonización, ayudan a crear un mundo que se desenvuelve sobre sí mismo. Sin duda esta tendencia hace pensar en una arqueología cooptada, sesgada, orientada a satisfacer intereses económicos e ideológicos. El panorama es sin duda desalentador. Entonces, ¿qué hacer? Las opciones son diversas. La primera es no tomar en serio que todo está perdido, que la única opción para habitar un sitio arqueológico es poner una tienda de suvenires con dinero dado por una agencia de cooperación internacional. Un primer paso para ello es develar los mecanismos a través de los cuales se crean estos paisajes de la diferencia y el consumo cultural, y así mismo, cómo esos estados que promueven la cooperación internacional, crean modelos de extracción de materias primas a costa de la calidad ambiental de las regiones en las que se "coopera". En este sentido, habría que trabajar en comprender cómo la diferencia es construida como una mercancía que se consume por sujetos ávidos de experiencias con la alteridad. De tal suerte, sería posible abandonar la idea de que los indígenas son elementos decorativos del paisaje, y llamar la atención sobre la necesidad de verlos como sujetos contemporáneos que luchan por su autonomía territorial y política en un mundo que se orienta hacia la consolidación de monopolios. También significa reconocer que estos territorios considerados ancestrales también son habitados por comunidades campesinas que tienen una historia con el lugar que debe ser visibilizada y comprendida. Esto significa ser crítico con las políticas culturales de la modernidad tardía y, más específicamente, implica ser críticos con las construcciones que la arqueología supone como instrumento de configuración de las temporalidades funcionales al capitalismo. La defensa del patrimonio, el empoderamiento local, son lemas que suenan bien pero que mirados al detalle, dan cuenta de procesos complejos de estandarización de la cultura, apertura de mercados de extracción y cooptación de recursos locales de gestión. Un segundo paso, es permitir configuraciones de la arqueología siguiendo las reglas del proyecto moderno de una ciencia horizontal en manos de la ciudadanía. De tal suerte, la sociedad tiene derecho a establecerse preguntas que deben ser resueltas por las agendas de investigación arqueológica; esto supone que la academia no debe ser un centro de tecnificación para el desarrollo industrial y posindustrial (como ocurre con la arqueología cuyos practicantes en porcentajes alarmantes están al servicio de la empresa privada), sino que debe suponer un espacio de crítica, de develación de las formas como la economía de mercado supone una monetarización de la cultura, el tiempo y el espacio. Esto implica la formu- 
lación de un nuevo contrato de la arqueología, un espacio que debe ser desarrollado con paciencia. En algún sentido, un nuevo contrato arqueológico supondrá transitar estos senderos de la develación, y alimentar programas de re-ocupación de sitios. También debe permitir pasar de una ideología multicultural (todos felices dentro de las economías capitalistas) a una intercultural (todos contemporáneos construyendo colectivos que son más que la suma de sus partes). Pienso que desde la interculturalidad, se podría pensar en un proyecto, para Ciudad Perdida, donde los campesinos e indígenas sean los propios investigadores del sitio permitiendo no sólo la conservación sino la investigación del área. Por ejemplo, en las visitas que he hecho, muchos guías enfatizan en relatar una memoria reciente (desde la década de 1970) que mezcla guaquería con violencia. La visita al sitio, debería contar esa historia y permitir reflexionar sobre el impacto del consumo de precolombinos por europeos en las sociedades campesinas de la Sierra Nevada de Santa Marta. Se deben abrir, en consecuencia, las puertas para una era post-patrimonial. De alguna manera estos escenarios se han ido tejiendo. La llegada de este periodo, si se permite la licencia cronológica, ya ha comenzado. Hay una serie de nuevos arqueólogos que están cuestionando las maneras como se hace arqueología en el mundo del capitalismo tardío. Los trabajos de Carina Jofré (Jofré, Biasatti, Galimberti, Najle \& Aroca, 2008) y Alejandro Haber (2015) en el noroeste argentino, los de Patricia Ayala en el norte de Chile (Ayala, Avendaño \& Cárdenas, 2003), los de Hugo Benavides en Ecuador (2001), los de Dante Angelo en Bolivia (2005), los de Cristóbal Gnecco (2012) en Colombia, señalan claramente que hay nuevas posibilidades de una práctica académica que sea útil en el doble propósito de conocer el pasado y ser críticos con un presente determinado por fuerzas sociales que se pretenden naturalizar. Se debe aclarar que esta doble intencionalidad no es jerarquizada, sino que ocurre simultáneamente, pues toda enunciación del pasado es un comentario del presente. Luego debe existir la posibilidad de comentar los mar- cos con los cuales se establecen las posibilidades de enunciación sobre el pasado para que, democráticamente, las personas sepan los límites epistémicos y políticos que se movilizan en su construcción.

\section{REFERENCIAS BIBLIOGRÁFICAS}

Angelo, D. (2005). La arqueología en Bolivia. Reflexiones sobre la disciplina a inicios del siglo XXI. Arqueología Suramericana, 1(2), 185-211.

Appadurai, A. (2000). Grassroots globalization and the research imagination. Public culture, 12(1) ,1-19.

Ayala, P., Avendaño, S. \& Cárdenas, U. (2003). Vinculaciones entre una arqueología social y la comunidad indígena de Ollagüe (Región de Antofagasta, Chile). Chungará (Arica), 35(2), 275-285.

Benavides, O.H. (2001). Returning to the source: social archaeology as Latin American philosophy. Latin American Antiquity, 12(4), 355-370. Byrne, D. (1991). Western hegemony in archaeological heritage management. History and Anthropology, 5(2), 269-276.

Corte constitucional de Colombia. (2014). Sentencia C-572/14. Recuperado de: http://www.corteconstitucional.gov.co/ relatoria/2014/C-572-14.htm

Dever, A. (2007). Social and economic development of a specialiazed community in Chengue, Parque Tairona. Faculty of Arts and Sciences. University of Pittsburg, Pittsburg, EE.UU.

Giraldo, S. (2010). Lords of the snowy ranges: politics, place, and landscape transformations in two Tairona towns in the Sierra Nevada de Santa Marta. Universidad del Chicago, Chicago, EE.UU.

Gnecco, C. (2012). Arqueología multivocal. Notas intempestivas. Complutum 23(2), 93-102.

Gnecco, C. y Ayala, P. (2010) Ed. Pueblos indígenas y arqueología en América Latina. Bogotá, Universidad de los Andes y Fundación de Investigaciones Arqueológicas Nacionales. 
Gómez, Y. (2005). Política científica colombiana y bibliometría: usos. Nómadas, 22, 241-254.

González, A. (2014). Malos nativos: una crítica de las arqueologías indígenas y poscoloniales. Revista de arqueología 27(2):47-63.

Guilland, M. \& Ojeda, D. (2013). Indígenas "auténticos" y campesinos "verdes". Los imperativos identitarios del turismo en Colombia. Cahiers des Amériques latines 71. Recuperado de: URL: http://cal.revues.org/2689

Haber, A. (2015). Contratiempo: Contract archaeology or a trench in the battle for the dead. International journal of historical archaeology 19(4), 736-747

Hamilakis, Y. (2005). Whose world and whose archaeology? The colonial present and the return of the political. Archaeologies 1(2), 94-101.

Hamilakis, Y. (2015). Arqueología y los sentidos. Experiencia, memoria y afecto. Madrid, JAS.

Jofré, C., Biasatti, S., González, G., Galimberti, S., Najle, N. \& Aroca, P. (2008). La Cayana: entre" lo arqueológico" y" lo cotidiano". Tensiones y resistencias en las versiones locales del" patrimonio arqueológico" en el norte de San Juan. Relaciones, Sociedad Argentina de Antropología, (33), 181-208.

Langebaek, C. (2005). Poblamiento prehispánico de las bahías de Santa Marta. Contribución al estudio de los cacicazgos Tairona del norte de Colombia. Bogotá. Universidad de los Andes y Universidad de Pittsburgh.
Londoño, W. (2013). Arqueología para el desarrollo y arqueología del desarrollo: Una visión desde Colombia. En: A. Herrera (Ed). Arqueología y desarrollo en América del Sur (pp. 147-166). Universidad de los Andes, Bogotá

Colombia. (2013) Ministerio de Ambiente y Desarrollo. Resolución 070 del 28 de febrero del 2013. Recuperado de: https://www.parquesnacionales.gov.co/PNN/portel/libreria/ pdf/res_0070_280213_pnn.pdf

Montaña, M. (2012). Las paradojas del desarrollo económico, social y ambiental frente a los derechos fundamentales de los pueblos indígenas - SNSM. Zhigoneshi, Revista de la Organización Indígena Gonawindua Tayrona. 14(12), 10-17

Organización wiwa yugumaiun bunkwanarrwa tayrona, Organización indígena kankuama, Organización gonawindua tayrona, Confederación indígena tayrona. (1999). Declaración conjunta de las cuatro organizaciones indigenas de la Sierra Nevada de Santa Marta para la interlocución con el estado y la sociedad nacional. Recuperado de: http://www. nacionmulticultural.unam.mx/movimientosindigenas/docs/decl_015.pdf

Žižek, S. 2011. ¡Bienvenidos a tiempos interesantes! La Paz, Vicepresidencia de la república de Bolivia. 